\title{
Cluster headache in Greece: an observational clinical and demographic study of 302 patients
}

Michail Vikelis ${ }^{1,2^{*}}$ and Alan M. Rapoport ${ }^{3}$

\begin{abstract}
Background: Cluster headache $(\mathrm{CH})$ is considered the most excruciating primary headache syndrome; although much less prevalent than migraine, it is not rare as it affects more than 1/1000 people. While its clinical presentation is considered stereotypic, atypical features are often encountered. Internationally, cluster headache is often misdiagnosed, undertreated and mistreated.
\end{abstract}

Methods: We prospectively studied $302 \mathrm{CH}$ patients, all examined by the same headache specialist. The aim of our study was to describe the demographic and clinical characteristics of $\mathrm{CH}$ patients in Greece and draw attention to under-management, under-treatment and mis-treatment often encountered in clinical practice; our purpose is to improve recognition and successful treatment of cluster patients by Greek neurologists and other physicians.

Results: In the present cohort, clinical characteristics of $\mathrm{CH}$ are similar to those described in other populations. Beyond the standard clinical characteristics, features like side shifts (12.6\%), location of maximal pain intensity outside the first trigeminal branch division (10.2\%), lack of autonomic features (7\%), presence of associated features of migraine and aggravation by physical activity (10\%) were encountered. Four out of five patients had consulted a physician prior to diagnosis. The median number of physicians seen prior to diagnosis was 3 and the median time to diagnosis was 5 years, though it improved for patients with recent onset. Chronic cluster headache, side shifts, pain location in the face or the back of the head and aggravation by physical activity were found, among others, to be statistically significantly related to delayed diagnosis or more physicians seen prior to diagnosis. Even properly diagnosed patients were often undertreated or mistreated.

Conclusions: Cluster headache, in a large cohort of Greek patients, has the same phenotypic characteristics as described internationally. Uncommon clinical features do exist and physicians should be aware of those, since they may eventuate in diagnostic problems. Most $\mathrm{CH}$ patients in Greece remain misdiagnosed or undiagnosed for rather lengthy periods of time, but time to diagnosis has improved recently. Even after diagnosis, treatment received was suboptimal.

Keywords: Cluster headache, Episodic cluster headache, Chronic cluster headache, Cluster headache phenotype, Cluster headache demographics, Error, Delay, Misdiagnosis, Mismanagement, Mistreatment

\footnotetext{
* Correspondence: mvikelis@headaches.gr

${ }^{1}$ Headache Clinic, Mediterraneo Hospital, Glyfada, Greece

${ }^{2}$ Glyfada Headache Clinic, 8 Lazaraki Str, Glyfada 16675, Greece

Full list of author information is available at the end of the article
} 


\section{Background}

Cluster headache $(\mathrm{CH})$, the most common trigeminal autonomic cephalalgia, is considered to be the most excruciating form of primary headache, causing profound ictal disability to sufferers [1, 2]. Although cluster headache was described long ago by a variety of names, systematic study of its clinical characteristics and significant advances in understanding its pathophysiology, began taking place only in the last $40-50$ years, pioneered by the work of Dr. Lee Kudrow [3, 4]. He studied oxygen inhalation therapy as a way to abort attacks; the importance of light and flying through time zones as triggers; and predicted that the hypothalamus was a critically important area of the brain involved in its pathophysiology $[3,4]$. From a clinical, pathogenic and therapeutic point of view, $\mathrm{CH}$ is distinct from other primary head syndromes such as migraine [1-6]. Cluster headache attacks are stereotypical and the usual clinical characteristics include side-locked pain episodes that are accompanied by ipsilateral cranial autonomic symptoms, most often lacrimation, conjunctival injection and rhinorrhea. The attacks are relatively short-lasting, usually 45-90 min and may differ in duration, frequency, intensity of pain and presence of autonomic symptoms [1-7]. Cluster headache is well described and characterized within the International Classification of Headache Disorders and may be diagnosed as episodic or chronic, the latter one characterized by $\mathrm{CH}$ attacks for more than a year with no remission or with remission for less than a month [8]. The disorder is more prevalent in men, although the male to female varies across studies [9].

Although often described by the word "rare" [10], $\mathrm{CH}$ is not actually rare, as its prevalence in population-based samples is estimated to be about $1 / 1000$ [9], which is comparable to that of multiple sclerosis [11]. Still, worldwide, $\mathrm{CH}$ is considered to be largely underdiagnosed and undertreated, as a significant percentage of $\mathrm{CH}$ patients are not treated according to existing guidelines or evidence-based treatment recommendations $[12,13]$.

Characteristics of $\mathrm{CH}$ patients in various countries [7, 14-17] and diagnostic and therapeutic trends and issues [7, 18-21] have been described in a number of publications, but so far no epidemiologic data have been published from Greece. We prospectively studied a large number of $\mathrm{CH}$ patients visiting two specialized headache clinics, located in Glyfada, Greece, and examined by the same headache specialist. The aim of our study was to describe the demographic and clinical characteristics of $\mathrm{CH}$ patients in Greece; in so doing, we hoped to draw attention to under-management and under-treatment often encountered in clinical practice, with the purpose of improving recognition and successful treatment by Greek neurologists and other physicians.

\section{Methods}

This study was a prospective clinical study, conducted in accordance with the principles of the Helsinki Declaration. Written informed consent was obtained from every patient. The study was approved by the first author's Institutional Review Board (Mediterraneo Hospital, protocol no. 1640). Data on consecutive $\mathrm{CH}$ patients $(n=302)$ were prospectively recorded in Glyfada Headache Clinic and in Mediterraneo Hospital Headache Clinic from February 2007 until June 2015. Patients came from all geographical regions of Greece, mainly through self-referral (84.7\%), although we did get referrals from other physicians, including neurologists. All patients were examined by the same headache specialist (MV). A detailed history was obtained through a semi-structured questionnaire, a complete neurological examination was performed, further examinations assessed or requested when needed and patients were finally assigned a diagnosis according to the International Headache Society (IHS) diagnostic criteria. After the publication of the last version of the International Classification of Headache Disorders (ICHD-III beta) [8], all previous cases were revisited and the IHS-III beta criteria were used for reconfirming diagnosis. All data were inserted in a database, double-checking for typing errors. Only data from patients diagnosed with cluster headache according to the IHS-III beta criteria (digit codes 3.1.1 and 3.1.2) were entered into the database and further analyzed. $\mathrm{X} 2$ test of independence or Fisher's exact test was used to evaluate the association between two qualitative variables. Kruskal-Wallis or Mann-Whitney test was used to evaluate the association between groups and the continuous characteristics of the sample (eg. age, etc.). Nominal variables are presented in absolute and relative (\%) frequencies, while continuous variables are presented by median and range or mean and standard deviation. The $5 \%$ significance level (alpha $=0.05$ ) was considered as statistically significant. All statistical analyses were performed with version 20 of the SPSS package (SPSS Inc, Chicago, Il, USA).

\section{Results \\ Demographics and $\mathrm{CH}$ types}

Our cohort is comprised of 302 Greek patients with cluster headache. The mean duration of follow up was 28.4 months. As expected, $\mathrm{CH}$ was more common in men than in women; 237 of our patients (78.5\%) were men while $65(21.5 \%)$ were women, resulting in a maleto-female ratio of 3.6:1. Most patients were diagnosed with episodic cluster headache (ECH) (234/302, $77.5 \%)$. Chronic cluster headache $(\mathrm{CCH})$ was diagnosed in $68 /$ $302(22.5 \%)$. Women accounted for $21.4 \%$ in the $\mathrm{ECH}$ group and $22.1 \%$ in the $\mathrm{CCH}$ group, resulting to a similar male-to-female ratio in both groups. The male to female ratio was found to decrease with the decade of onset, from $6: 1$ for onset before 1989 , to $4.3: 1$ for onset 
between 1990 and 1999, 4.2:1 for onset from 2000 to 2009 and 2.3/1 for onset since 2010, though this change did not reach statistical significance $(p=0.139)$ (Table 1$)$.

\section{CH family history and social habits}

A positive family history of $\mathrm{CH}$ was reported by $17.5 \%$ of patients $(16.7 \%$ in $\mathrm{ECH}$ and $20.6 \%$ in $\mathrm{CCH})$ and in most cases involved a parent with similar symptoms (usually undiagnosed, but with typical witnessed clinical description). Smoking was quite common, with the majority of our patients reporting being current $(61.3 \%)$ or past smokers (12.9\%). Current alcohol consumption was reported by $58.3 \%$ of the patients, while $16.9 \%$ of them were former alcohol users. Alcohol was reported as a trigger for $\mathrm{CH}$ attacks by $84,8 \%$ of males and $45,3 \%$ of females $(p=0.001)$. Use of recreational illegal substances was reported by $14.9 \%$ as current and by $15.6 \%$ as prior. Most of $\mathrm{CH}$ patients in our series worked on a regular basis (or were full-time students) (63\%), but $21 \%$ were unemployed and $16 \%$ worked occasionally.

\section{$\mathrm{CH}$ onset and course}

The median age at onset of $\mathrm{CH}$ in our series was 29 years of age (mean: 32 years), with the youngest patient reporting disease onset at the age of 8 and the oldest at the age of 67 (both were ECH patients). In the ECH group, median age of onset was 29 years (mean 31.5 years), while in the $\mathrm{CCH}$ group, the median age of onset was 30 years (mean 33.2 years). The youngest and oldest age at onset was 8 and 68 years for men and 12 and 67 years for women, respectively. In $\mathrm{CCH}$ the youngest reported age of onset was 13 years and the oldest was 66 years of age. In $\mathrm{ECH}$, the vast majority started as episodic, but 8 patients out of 234 (3.3\%) evolved from an initially chronic form. In $\mathrm{CCH}, 50$ out of 68 patients $(73.5 \%)$ patients experienced $\mathrm{CCH}$ since onset, while in 18 of them (26.5\%) $\mathrm{CH}$ evolved from an initially episodic form.

\section{Clinical features \\ Pain location}

In our cohort, pain was reported to localize in various areas, including the orbital, supraorbital and temporal area, but also the occiput, the upper and lower teeth, the jaw, the nose, the cheek, the neck, the ear, the shoulder and the vertex (Table 2). Still, the orbital, supraorbital

Table 1 Male to female ratio by decade of onset

\begin{tabular}{lllc}
\hline $\begin{array}{l}\text { Decade of } \\
\text { onset }\end{array}$ & $\begin{array}{l}\text { Males } \\
(N=237)\end{array}$ & $\begin{array}{l}\text { Females } \\
(N=65)\end{array}$ & $\begin{array}{l}\text { Male to } \\
\text { female ratio }\end{array}$ \\
\hline$<1989$ & 26 & 4 & 6 \\
$1990-1999$ & 56 & 13 & 4.3 \\
2000-2009 & 100 & 24 & 4.2 \\
2010-present & 55 & 24 & 2.3 \\
\hline
\end{tabular}

Table 2 Site of pain (\%, N=302, unless otherwise indicated)

\begin{tabular}{lccccc}
\hline & Total & ECH & CCH & Men & Women \\
\hline Orbital (\%) & 91.7 & 92.3 & 89.7 & 93.2 & 86.2 \\
Supraorbital (\%) & 56.6 & 56.4 & 57.4 & 56.1 & 58.5 \\
Temporal (\%) & 75.5 & 75.2 & 76.5 & $78.1^{*}$ & $66.2^{*}$ \\
Occiput (\%) & 45.0 & 45.7 & 42.6 & 47.3 & 36.9 \\
Upper teeth (\%) & 26.2 & 24.4 & 32.4 & 26.2 & 26.2 \\
Lower teeth (\%) & 12.3 & 11.5 & 14.7 & 12.2 & 12.3 \\
Jaw (\%) & 18.5 & 17.9 & 20.6 & 20.7 & 10.8 \\
Cheek (\%) & 24.2 & 21.8 & 32.4 & 26.6 & 15.4 \\
Nose (\%) $(N=299)$ & 10.0 & 9.5 & 11.8 & 10.6 & 7.8 \\
Ear (\%) $(N=301)$ & 10.0 & 9.9 & 10.3 & 9.3 & 12.5 \\
Neck (\%) & 15.9 & $13.2^{*}$ & $25.0^{*}$ & 16 & 15.4 \\
Shoulder (\%) $(N=300)$ & 6.7 & $3.9^{*}$ & $16.2^{*}$ & 7.2 & 4.7 \\
Vertex (\%) $(N=293)$ & 24.7 & $21.5^{*}$ & $36.9^{*}$ & 23.9 & 28.6 \\
\hline
\end{tabular}

*Indicates statistically significant difference between two groups (see text for exact $p$ value)

and temporal areas were most commonly involved (in 91.7, 56.6, and $75.5 \%$ of patients, respectively) with $48 \%$ of our patients reporting pain in all three of these areas. It is worth mentioning that 5 patients were excluded from this analysis as they reported no pain in any of these three areas and as such they did not fulfill criterion $\mathrm{B}$ of the International Headache Society [8]. They were otherwise typical $\mathrm{CH}$ patients. The majority of our patients reported maximal pain intensity in the orbital, supraorbital and temporal area (68.5, 7.3 and $13.6 \%$, respectively), as typically described. It should be noticed however that additional areas, rather atypical for maximal pain intensity, have been occasionally reported, such as the occiput ( $4 \%$ of the group), the vertex (1\% of the group), the upper teeth ( $2 \%$ of the group) and the cheek ( $2.6 \%$ of the group), while 2 patients had maximal pain intensity in the neck and one in the jaw. No significant differences in the areas involved were noticed between men and women, except for the temporal area, which was more frequently involved in men $(P=0.048)$. Finally, the neck, shoulder and vertex as pain localizations were significantly more frequently reported in the $\mathrm{CCH}$ group ( $p=0.02,0.001$ and 0.01 , respectively) as compared to the ECH group (Table 2).

\section{Side of pain, laterality, side shifts}

While the majority of our patients experienced strictly unilateral pain $(87.4 \%$ of total, right sided $47.0 \%$ and leftsided $40.4 \%$ ) without a side shift, $12.6 \%$ reported at least one type of a side shift, most commonly a side shift between bouts $(9.0 \%)$, followed by side shift within bouts (3.0\%) and side shift within attacks (1.7\%). In the subgroup of episodic cluster headache, $0.9 \%$ had experienced a side shift within an attack, $2.1 \%$ had experienced a side 
shift within a bout and $10.4 \%$ had experienced a shift between bouts (shift to the other side at the beginning of a new bout). In the $\mathrm{CCH}$ group, side shift within attacks was reported by $4.4 \%$ of patients, while side shift within bouts was reported by $5.9 \%$ and side shift between bouts by $4.4 \%$ of patients (when periods of remission were reported in the history of a $\mathrm{CCH}$ patient, Table 3). One single patient that evolved from episodic to chronic cluster headache later in the course of his disease developed a side shift between attacks and subsequently a side shift within attacks. During the within-attack side shifts, the pain was reported to be simultaneously present in both the right and left orbital and supraorbital area, at high intensity, accompanied by bilateral autonomic features, a characteristic that has been previously reported in other $\mathrm{CCH}$ patients [17]. Side shift within attacks and within bouts was more frequently reported in the $\mathrm{CCH}$ than in the ECH group while any type of side shift was more common in men that in women, although the differences identified did not reach statistical significance (Table 3).

\section{Autonomic and associated features, character of pain}

The most commonly reported autonomic feature was lacrimation, followed by nasal congestion/rhinorrhea and conjunctival injection (detailed percentages in Table 4). It should be noted that 21 patients ( $7 \%$ of total) in our cohort had none of the autonomic features listed in the criterion $\mathrm{C} 1$ of the ICHD-III beta [8]. Absence of autonomic features was more prevalent in women that in men ( $4.6 \%$ of males vs. $15.4 \%$ of females had no autonomic features, $p=0.003$ ). Patients with no autonomic features tended to have disease onset at an older age than those with at least one autonomic feature (median age of disease onset 43 vs. 29 years, but this difference did not reach statistical significance; $p=0.064$ ). In between sex comparison, lacrimation and conjunctival injection were less frequently reported in women than in men $(p=0.031$ and $p=0.026$, respectively), while no differences were noticed between $\mathrm{ECH}$ and $\mathrm{CCH}$. It is also worth mentioning that autonomic features added in criterion $\mathrm{C}$ of ICHD-III beta for $\mathrm{CH}$, namely ipsilateral sensation of fullness in the ear

Table 3 Side of pain, laterality, side shifts (\%, N=302, unless otherwise indicated)

\begin{tabular}{lrrrrc}
\hline & Total & ECH & CCH & Men & Women \\
\hline Strictly unilateral (\%) & 87.4 & 86.3 & 91.1 & 86.4 & 90.8 \\
Strictly left (\%) & 40.4 & 39.7 & 42.6 & 40.9 & 38.5 \\
Strictly right (\%) & 47.0 & 46.6 & 48.5 & 45.6 & 52.3 \\
$\begin{array}{l}\text { Side shift between bouts (\%) } \\
(N=299)\end{array}$ & 9.0 & 10.4 & 4.4 & 9.8 & 6.2 \\
$\begin{array}{l}\text { Side shift within bouts (\%) } \\
\text { (N=301) }\end{array}$ & 3.0 & 2.1 & 5.9 & 3.4 & 1.5 \\
Side shift within attacks (\%) & 1.7 & 0.9 & 4.4 & 2.1 & 0.0 \\
\hline
\end{tabular}

Table 4 Autonomic features (\%, $N=302$, unless otherwise indicated)

\begin{tabular}{lrrrrc}
\hline & Total & ECH & CCH & Men & Women \\
\hline Lacrimation (\%) & 82.8 & 83.3 & 80.9 & $85.2^{*}$ & $73.8^{*}$ \\
Conjunctival injection (\%) & 66.9 & 64.5 & 75.0 & $70.0^{*}$ & $55.4^{*}$ \\
$\begin{array}{l}\text { Nasal congestion and/or } \\
\text { rhinorrhea (\%) }\end{array}$ & 77.1 & 78.1 & 73.5 & 78.8 & 70.8 \\
$\begin{array}{l}\text { Eyelid oedema (\%) } \\
\text { Forehead and facial }\end{array}$ & 35.4 & 35.5 & 35.3 & 36.7 & 30.8 \\
$\begin{array}{l}\text { sweating (\%) } \\
\text { Miosis and/or ptosis (\%) }\end{array}$ & 19.2 & 20.5 & 14.7 & 198 & 16.9 \\
$\begin{array}{l}\text { None of the above (\%) } \\
\text { Forehead and facial flushing (\%) }\end{array}$ & 27.6 & 34.8 & 33.8 & 36.4 & 27.7 \\
$(N=133)$ & 7.0 & 6.4 & 8.8 & $4.6^{*}$ & $15.4^{*}$ \\
$\begin{array}{l}\text { Sensation of fullness in the ear (\%) } \\
(N=128)\end{array}$ & 28.1 & 28.3 & 27.6 & 26.9 & 27.6 \\
\hline
\end{tabular}

*Indicates statistically significant difference between two groups (see text for exact $p$ value)

and ipsilateral forehead/facial flushing, were rather commonly reported in our group, by 28.1 and $27.1 \%$ of patients, respectively (data available only for a third of total group) (Table 4). Despite that, there was not a single case of a patient without presence of any of the autonomic features included in the ICHD-II (conjunctival injection and/or lacrimation, nasal congestion and/or rhinorrhea, eyelid oedema, forehead and facial sweating) in whom forehead and facial flushing or sensation of fullness in the ear was reported. Associated features considered typical for migraine but often disregarded in $\mathrm{CH}$ were also quite common (Table 5). Among them, photophobia was the

Table 5 Associated features and character of pain $(\%, N=302$, unless otherwise indicated)

\begin{tabular}{lrrrrc}
\hline & Total & ECH & CCH & Men & Women \\
\hline Photophobia (\%) & 61.6 & 60.3 & 66.2 & 61.6 & 61.5 \\
Phonophobia (\%) & 36.8 & 34.6 & 44.1 & 38.0 & 32.3 \\
Nausea (\%) & 22.8 & 22.2 & 25.0 & 23.6 & 20.0 \\
Vomiting (\%) ( $N=301)$ & 7.0 & 6.9 & 7.4 & 7.6 & 5.7 \\
Belching (\%) (N=300) & 21.0 & 21.0 & 20.9 & 22.0 & 17.2 \\
Yawning (\%) & 19.5 & 18.4 & 23.5 & 21.1 & 13.8 \\
Sense of restlessness or & 83.4 & 82.8 & 85.3 & 85.7 & 75.0 \\
agitation (\%) ( $N=301)$ & & & & & \\
Pain aggravation by physical & 10.0 & 9.9 & 10.3 & 8.5 & 15.4 \\
activity ( $=301)$ & & & & & \\
Stabbing/lancinating pain (\%) & 88.7 & $90.6^{*}$ & $82.4^{*}$ & 89.9 & 84.6 \\
Throbbing pain (\%) & 7.3 & $6.4^{*}$ & $10.3^{*}$ & 7.6 & 6.2 \\
Pressing pain (\%) & 1.3 & 1.7 & 0.0 & 1,3 & 1.5 \\
Other type of pain (\%) & 2.6 & $1.3^{*}$ & $7.4^{*}$ & 1.3 & 7.7 \\
$\begin{array}{l}\text { Attacks triggered by alcohol } \\
\text { ( } n=301 \text { ) }\end{array}$ & 76.4 & 74.7 & 82.4 & $84.8^{*}$ & $45.3^{*}$ \\
\hline
\end{tabular}

*Indicates statistically significant difference between two groups (see text for exact $p$ value) 
most prevalent (61.6 \%) in our cohort and, when present, in most patients it was reported to be lateralized to the suffering side. Phonophobia, nausea and vomiting were also reported (Table 5). In addition, yawning and belching just preceding or during the final phase of an attack were reported by approximately one out of five patients. Another $\mathrm{CH}$ characteristic that is included in the IHS classification criteria, a sense of restlessness or agitation during attacks, was reported by $83.4 \%$ of our patients and was less common in women than in men (75 \% vs. $85.7 \%$, $p=0.042$ ). However, It should be noted that $10.0 \%$ of our group reported pain aggravation by physical activity and the majority of them preferred to stand still or lay down during attacks. This represents a quite atypical feature, compared to classical cluster headache descriptions. The character of pain, as expected, was described as lancinating or stabbing in the vast majority of patients, followed by throbbing or pressing pain (Table 5). Patients with $\mathrm{CCH}$ had a lower percentage of stabbing/lancinating pain (82.4 \%) in comparison to those with $\mathrm{ECH}(90.6 \%)$ and a higher percentage of throbbing pain $(10.3 \%$ vs. $6.4 \%)$ and any other kind of pain (mainly burning pain) $(7.4 \%$ vs. $1.3 \%)$ ( $p=0.019$ for these comparisons).

\section{Attack duration and frequency, bout duration, periodicity}

Some characteristics of $\mathrm{CH}$, including attack duration and frequency, may vary within the same patient during a cluster period. Shorter or less frequent attacks may be encountered at the beginning or ending of a bout and longer and more frequent attacks at the peak. in order to better describe the clinical features, we recorded not only the usual or typical duration or frequency of attacks but also the usual minimum and maximum values for those. The median usual duration of attacks was $60 \mathrm{~min}$ for both $\mathrm{ECH}$ and $\mathrm{CCH}$ patients, while the median usual minimum attack duration was $40 \mathrm{~min}$ ( 45 for $\mathrm{ECH}$ and 30 for $\mathrm{CCH}$, respectively, $p=0.009$ ), and the median usual maximum attack duration was 90 min (for both
$\mathrm{ECH}$ and $\mathrm{CCH}$ ). It should be noted that in some patients maximum attack duration in individual attacks exceeded $180 \mathrm{~min}$ and reached up to $420 \mathrm{~min}$ (Table 6). The median number of attacks per day was 1 ( 1 for $\mathrm{ECH}$ and 2 for $\mathrm{CCH}, p=0.001$ ), while the median usual maximum number of attacks per day was 3, 2 and 3.5 for total group, $\mathrm{ECH}$ and $\mathrm{CCH}$, respectively $(p=0.001$ for $\mathrm{ECH}$ vs. $\mathrm{CCH}$ ). The median number of bouts per year was 1 (range: 0.1-6). The median usual duration of bouts for ECH was 4 weeks (range: 1-24 weeks). Seasonal propensity of bout onset for ECH was reported by $46.2 \%$ patients in our cohort, while a daily propensity of attack onset (mainly nocturnal) was reported by $47 \%$ of total cohort and was significantly more common in $\mathrm{ECH}$ than $\mathrm{CCH}(53.8 \%$ vs. $23.5 \%, p=0.001)$.

\section{Diagnostic and therapeutic issues}

In the majority of our patients (175/302) a diagnosis of $\mathrm{CH}$ had not been previously made and was established during consultation at our Center for the first time. Among the 127 previously diagnosed patients, most of them were diagnosed by a neurologist (70.2 \%), followed by a primary care physician, neurosurgeon and ENT specialist, (5.6, 4.8, $3.2 \%$ respectively). Overall, $87.4 \%$ of patients were diagnosed by a neurologist, including patients diagnosed at our clinic. Interestingly, 39 cases $(12.9 \%$ of total), reported a self-diagnosis, primarily through information found on the internet, with subsequent medical confirmation. In the majority of these cases, one or more erroneous diagnoses had been made by physicians previously. Hence, self-diagnosis was the second more common way of diagnosis, a fact indicating the importance of medical information provided to public. The median time from disease onset to diagnosis in our cohort was 5 years (range $0-45$, mean 7.2 years). Overall, time to diagnosis significantly improved with decade of onset, for the current decade being just one year (median), compared to 5 years for the 2000s, 12 years for the 1990s and 20 years for onset before 1990 (Table 7). This also

Table 6 Attack duration and frequency

\begin{tabular}{|c|c|c|c|c|c|c|}
\hline & \multicolumn{2}{|l|}{ Total group } & \multirow{2}{*}{$\begin{array}{l}\mathrm{ECH} \\
\text { Median (range) }\end{array}$} & \multirow{2}{*}{$\begin{array}{l}\mathrm{CCH} \\
\text { Median (range) }\end{array}$} & \multirow{2}{*}{$\begin{array}{l}\text { Males } \\
\text { Median (range) }\end{array}$} & \multirow{2}{*}{$\begin{array}{l}\text { Females } \\
\text { Median (range) }\end{array}$} \\
\hline & Median (range) & Mean (SD) & & & & \\
\hline Usual attack duration (min) & $60(20-180)$ & $66.7(35.3)$ & $60(20-180)$ & $60(20-180)$ & $60(20-180)$ & $60(25-180)$ \\
\hline Usual minimum attack duration (min) & $40(5-180)$ & $44.3(30.5)$ & $45^{*}(10-180)$ & $30^{*}(5-90)$ & $40(5-180)$ & $30(10-180)$ \\
\hline Usual maximum attack duration (min) & $90(30-420)$ & $109.1(67)$ & $90(30-420)$ & $90(30-300)$ & $90(30-420)$ & $90(30-300)$ \\
\hline Usual attack frequency/24 h & $1(1-6)$ & $0.9(0.6)$ & $1^{*}(0.5-6)$ & $2^{*}(0.3-8)$ & $1(0.3-8)$ & $1(0.5-6)$ \\
\hline Usual maximum attack frequency/24 h & $3(0.5-10)$ & $2.9(1.7)$ & $2^{*}(1-10)$ & $3,5^{*}(0.5-9)$ & $3(1-9)$ & $3(0.5-10)$ \\
\hline Usual bout duration (weeks) & $6(1-52)$ & $16.1(19)$ & $4(1-24)$ & - & $7(1-52)$ & $6(1-52)$ \\
\hline Usual minimum bout duration (weeks) & $4(0.5-52)$ & $12.8(17)$ & $4(0.5-24)$ & - & $4(1-52)$ & $4(1-52)$ \\
\hline Usual maximum bout duration (weeks) & $8(0-52)$ & $16.6(17.7)$ & $8(0-50)$ & - & $8(1-52)$ & $8(1-52)$ \\
\hline
\end{tabular}

*Indicates statistically significant difference between two groups (see text for exact $p$ value) 
Table 7 Years from disease onset to diagnosis, correlated to decade of onset

\begin{tabular}{llllll}
\hline & $\begin{array}{l}\text { Tota } \\
\text { Median (range) }\end{array}$ & $\begin{array}{l}\text { ECH } \\
\text { Median (range) }\end{array}$ & $\begin{array}{l}\text { CCH } \\
\text { Median (range) }\end{array}$ & $\begin{array}{l}\text { Men } \\
\text { Median (range) }\end{array}$ & $\begin{array}{l}\text { Women } \\
\text { Median (range) }\end{array}$ \\
\hline $\begin{array}{llllll}\text { Decade of onset of CH } \\
<1989\end{array}$ & & & & & \\
$23(0-45)$ & $18(0-45)$ & $30(20-30)$ & $18(0-41)$ & $12(2-16)$ \\
$1990-1999$ & $12(2-21)$ & $11(2-21)$ & $13(2-16)$ & $5(0-21)$ & $3(0-14)$ \\
$2000-2009$ & $5(0-14)$ & $5(0-14)$ & $5(0-12)$ & $0-12)$ & $3(0-7)$ \\
$2010-$ present & $1(0-7)$ & $1(0-7)$ & $1(0-6)$ & $0-6)$ & \\
\hline
\end{tabular}

$p=0.001$ for all comparisons between subsequent decades, applies also to comparisons between subgroups

applied to all subgroups (males, females, $\mathrm{ECH}$ and $\mathrm{CCH}$ ) ( $p=0.001$ for all comparisons between subsequent decades, applies also to all subgroups).

In $245 / 302$ patients ( $81.1 \%$ of total group), medical consultation was sought prior to the diagnosis of $\mathrm{CH}$. In more detail, before being diagnosed, $63.5 \%$ of the total cohort had consulted a primary care physician (general practitioner or internist, in Greece), $35.5 \%$ an ENT specialist, $31.4 \%$ an ophthalmologist, $25.9 \%$ a dentist, $41.3 \%$ a neurologist and $8.5 \%$ a neurosurgeon, without having received a diagnosis of $\mathrm{CH}$. Half the patients in our cohort (51\%) had been diagnosed as migraineurs prior to $\mathrm{CH}$ diagnosis, $42.3 \%$ as suffering from trigeminal neuralgia, $11 \%$ as suffering from ophthalmic disease, $25.1 \%$ received an ENT disease diagnosis, $15.1 \%$ a dental problem/temporomandibular joint disorder diagnosis and $12 \%$ a cervical spine disorder diagnosis (Table 8). The median number of physicians seen prior to diagnosis was 3 (range $0-15$, mean 3.5 ) and significantly improved with decade of onset, from a median of 7 doctors seen prior to diagnosis for onset before 1989 to a median of 5, 3 and 1 for onset between 1990-1999, 2000-2009 and after 2009, respectively ( $p=0.001$ for all comparisons). Patients with $\mathrm{CCH}$ had seen a larger number of physicians prior to diagnosis than $\mathrm{ECH}$ sufferers (median 4 vs. $2, p=0.0001$ ), while number or physicians prior to diagnosis did not differ between males and females (median 3, in both cases).

Although time to diagnosis and number of physicians seen prior to diagnosis improved over time, we further

Table 8 Diagnoses made and physicians seen prior to $\mathrm{CH}$ diagnosis

\begin{tabular}{lllr}
\hline $\begin{array}{l}\text { A. Diagnoses made prior } \\
\text { to CH diagnosis (\%) }\end{array}$ & & $\begin{array}{l}\text { B. Physicians seen prior } \\
\text { CH to diagnosis (\%) }\end{array}$ \\
\hline Migraine & 51.0 & Primary care physician & 63.5 \\
Trigeminal neuralgia & 42.3 & Dentist & 25.9 \\
Ophthalmic disease & 11.0 & ENT specialist & 35.5 \\
Dental or jaw disease & 15.1 & Ophthalmologist & 31.4 \\
ENT disease & 25.1 & Neurologist & 41.3 \\
Cervical spine disease & 12.0 & Neurosurgeon & 8.5 \\
& & Other & 22.6 \\
\hline
\end{tabular}

investigated whether certain disease characteristics that were encountered less often or features that are considered atypical resulted in diagnostic delays. Factors identified as significantly correlated with greater number of years lapsed to diagnosis included earlier decade of onset, presence of side shift between bouts, pain location in the jaw, cheek, lower teeth or ear area, presence of photophobia, forehead and facial sweating, pain aggravation by physical activity and absence of typical cluster headache autonomic features (exact $p$ values presented at Table 9). In addition, factors associated with a greater number of physicians prior to diagnosis included presence of $\mathrm{CCH}$, earlier decade of onset, pain location in upper teeth, cheek, lower teeth, neck, nose, ear, shoulder or vertex, presence of eyelid oedema, miosis/ptosis and aggravation by physical activity (exact $p$ values presented at Table 10). Furthermore, increased usual and maximum duration of bouts and increased usual and maximum attack frequency were also correlated with seeing a larger number of physicians prior to diagnosis, though these correlations were weak (Table 10).

Cluster headache patients can be treated with evidence-based or guideline-recommended treatments $[10,13,22-26]$, but mistreatment is often reported [19-21] and treatments that are proven as not effective, as in the case of indomethacin [27] or single high dose steroids [28], or have unconfirmed efficacy, as in the case of octreotide [29] are internationally often used. Use of inappropriate treatments or procedures or lack of recommendation of appropriate treatment was often encountered in our cohort, not only in undiagnosed patients but, importantly, also in patients previously diagnosed. Among the total group, 188 patients $(62.7 \%)$ had received pharmaceutical treatment of any type prior to $\mathrm{CH}$ diagnosis and 42 patients (14.0\%) had undergone unnecessary procedures, mainly by dentists (10.2 \%) and ENT specialists (9.9\%), most commonly tooth extractions, fillings, sinus washout or surgery for nasal septum deviation, in all cases without success. In a single patient with severe cheek/ jaw pain, all teeth on the upper jaw ipsilateral to pain had been extracted. Among the 127 previously diagnosed patients, only a minority had been offered treatment with subcutaneous sumatriptan or high flow oxygen for acute attacks or verapamil, corticosteroids or 
Table 9 Factors correlated with more years to diagnosis

\begin{tabular}{|c|c|c|}
\hline & Years to diagnosi & \\
\hline & Median (Range) & $p$-value \\
\hline Decade of onset & & 0.001 \\
\hline$<2000$ & $13(0-45)$ & \\
\hline 2000-2009 & $5(0-14)$ & \\
\hline$\geq 2010$ & $1(0-7)$ & \\
\hline Side shift between bouts & & 0.008 \\
\hline No & $5(0-45)$ & \\
\hline Yes & $8(0-26)$ & \\
\hline Jaw location of pain & & 0.002 \\
\hline No & $5(0-30)$ & \\
\hline Yes & $7(0-45)$ & \\
\hline Cheek location of pain & & 0.015 \\
\hline No & $5(0-30)$ & \\
\hline Yes & $7(0-45)$ & \\
\hline Lower teeth location of pain & & 0.015 \\
\hline No & $5(0-30)$ & \\
\hline Yes & $10(0-45)$ & \\
\hline Ear location of pain & & 0.041 \\
\hline No & $5(0-41)$ & \\
\hline Yes & $10(0-45)$ & \\
\hline Photophobia & & 0.016 \\
\hline No & $4(0-30)$ & \\
\hline Yes & $6(0-45)$ & \\
\hline Aggravation by physical activity & & 0.008 \\
\hline No & $3(0-20)$ & \\
\hline Yes & $6(0-45)$ & \\
\hline Forehead and facial sweating & & 0.018 \\
\hline No & $5(0-30)$ & \\
\hline Yes & $6(0-45)$ & \\
\hline Absence of autonomic features & & 0.023 \\
\hline No & $2(0-14)$ & \\
\hline Yes & $5(0-45)$ & \\
\hline
\end{tabular}

lithium for prevention (Table 11). In addition, a substantial proportion was offered treatment with carbamazepine, flunarizine, antidepressants or alternative treatments. Use of recommended treatments, such as sc sumatriptan, $\mathrm{O} 2$ inhalation, corticosteroids or verapamil did not seem to be much more common even among previously diagnosed patients who had been diagnosed by a neurologist (Table 11).

\section{Discussion}

Although less common than other primary headaches, cluster headache is not rare per se $[9,12,13]$. Still, worldwide it is reported to remain largely under-recognized and sub-optimally or poorly treated both in primary care and by specialists, despite the fact that its severity would warrant prompt diagnosis and treatment [7, 12, 18-21, 30]. Therefore, it is critical that all physicians be familiar with diagnosing and managing cluster headache. In order to improve recognition and successful treatment of $\mathrm{CH}$ by Greek neurologists and general physicians, we undertook the task of describing the demographic, clinical characteristics, diagnostic and treatment paths of a large cohort of $\mathrm{CH}$ patients, seen over a lengthy period of time by the same headache specialist.

Overall, our data are in line with previously published data from different countries $[5,7,14-17,31]$. As expected, the typical presentation of cluster headache in Greece is indisputably stereotyped and distinct from other primary headache syndromes. Still, our data show that $\mathrm{CH}$ is not a male disorder, as the female to male ratio for patients with disease onset during this decade has fallen to 2.3:1 from 6:1 twenty years ago, a finding that has been noticed long ago [32]. Clinical presentation of the disease was largely similar in both genders.

Features often considered uncommon or atypical were encountered in a significant percentage of patients in our cohort. Those included side shifts, maximal pain intensity outside the first division of the trigeminal nerve, lack of all autonomic features or lack of a sense of restlessness or agitation, as other studies have also shown $[5,7,16,33]$. Some of the atypical features, including side shifts, pain located in jaw, cheek, teeth, shoulder, vertex or neck area, were found in our study to be coexistent with, and maybe the cause of, delayed diagnosis and/or a larger number of physicians being consulted prior to diagnosis. In addition, migraine associated symptoms and autonomic features were often encountered, with photophobia being the most common, but not the only one reported in our series. This is in line with previously published data [7, 34, 35]. In our cohort, among migraine associated symptoms, aggravation by physical activity, reported by $10 \%$ of our patients, was related both to delayed diagnosis and a greater number of physicians being consulted prior to diagnosis. It is worth mentioning that even though the autonomic features added in criterion $\mathrm{C}$ of the revised criteria of the International Headache Society (ICHD-III beta) for $\mathrm{CH}$, (-namely ipsilateral sensation of fullness in the ear and ipsilateral forehead/facial flushing) were rather commonly reported in our group, there was not a single case of a patient without the presence of any of the autonomic features included in ICHD-II (conjunctival injection and/or lacrimation, nasal congestion and/or rhinorrhea, eyelid oedema, forehead and facial sweating) in whom forehead and facial flushing or sensation of fullness in the ear was reported. This supports the opinion that adding forehead and facial flushing and 
Table 10 Factors correlated with seeing increased number of physicians prior to diagnosis

\begin{tabular}{|c|c|c|c|c|c|}
\hline & Median (Range) & $p$-value & Miosis and/or ptosis & & 0.001 \\
\hline Number of physicians & & & $2(0-10)$ & $2(0-15)$ & \\
\hline CH subtype & & 0.001 & $2(0-10)$ & $4(0-15)$ & \\
\hline $\mathrm{ECH}$ & $2(0-15)$ & & Spearmans' rho & & \\
\hline $\mathrm{CCH}$ & $4(0-15)$ & & Usual maximum duration of bout & 0.208 & 0.001 \\
\hline Decade of onset & & 0.001 & Usual duration of bout & 0.224 & 0.001 \\
\hline$<2000$ & $5(0-15)$ & & Usual attack frequency & 0.220 & 0.001 \\
\hline 2000-2009 & $3(0-11)$ & & Usual maximum attack frequency & 0.310 & 0.001 \\
\hline
\end{tabular}

Upper teeth location of pain

No

Yes

Jaw location of pain

No

Yes

Cheek location of pain

$\begin{array}{ll}\text { No } & 2(0-15) \\ \text { Yes } & 5(0-15) \\ \text { Lower teeth location of pain } & \\ \text { No } & 3(0-15) \\ \text { Yes } & 5(0-15)\end{array}$

Neck location of pain

No

Yes

Nose location of pain

No

Yes

Ear location of pain

$\begin{array}{ll}\text { No } & 3(0-15) \\ \text { Yes } & 5(1-15)\end{array}$

Shoulder location of pain

$\begin{array}{ll}\text { No } & 3(0-15) \\ \text { Yes } & 8(1-11)\end{array}$

Vertex location of pain

No

Yes

Aggravation by physical activity

No

Yes

Eyelid oedema

$2(0-10)$

$2(0-10)$
$3(0-15)$

$4(0-15)$

$3(0-15)$

$4(0-15)$

$3(0-15)$

$5(0-15)$

$3(0-15)$

$5(0-15)$

$3(0-15)$

$4(0-10)$

$2(0-10)$

$3(0-15)$

$3(0-15)$

0.001

0.024

$4(0-15)$
Table 10 Factors correlated with seeing increased number of physicians prior to diagnosis (Continued)

sensation of fullness in the ear in ICHD-III beta provides no added diagnostic value [36].

Concerning diagnostic delays, our data are in line with other published studies, which have already shown that $\mathrm{CH}$ patients are often misdiagnosed and mistreated [7, 19, 20, 30, 37]. In our cohort, eight out of ten $\mathrm{CH}$ patients have consulted at least one physician without been diagnosed and more than $40 \%$ have consulted a neurologist. Furthermore, even in diagnosed patients, and despite the existence of evidence-based treatment options [10, 13, 22-26, 37, 38], use of guidelines or recommended treatments is quite low. These facts clearly point out the need for Continuous Medical Education in the field of cluster headache. Still, our study demonstrates that time to diagnosis is improving in Greece, something that might have to do with increasing access to specialized neurologic care and headache specialists. The role of medical information found mainly on the internet is increasingly important, as a significant percentage of patients in our group, despite having seen physicians, were actually self-diagnosed and self-referred to our center. In addition, despite these improvements, the typical sufferer still waits five years for a correct diagnosis and sees three

Table 11 Treatments offered to previously diagnosed patients, (\%)

\begin{tabular}{lcc}
\hline & $\begin{array}{c}\text { Overall \% } \\
(N=127)\end{array}$ & $\begin{array}{c}\text { Previously diagnosed by a } \\
\text { neurologist \% }(N=89)\end{array}$ \\
\hline Subcutaneous sumatriptan & 2.4 & 3.4 \\
O2 inhalation & 13.5 & 13.5 \\
Triptans orally & 31.0 & 33.7 \\
Corticosteroids orally & 43.7 & 44.9 \\
Verapamil & 18.3 & 20.2 \\
Lithium & 3.2 & 2.2 \\
Topiramate & 23.8 & 23.6 \\
Valproate & 6.3 & 6.7 \\
Carbamazepine & 18.3 & 15.7 \\
Flunarizine & 16.7 & 19.1 \\
Tricyclic antidepressants & 10.3 & 9.0 \\
SSRls, SNRls & 11.1 & 10.1 \\
Alternative treatments & 28.2 & 32.2 \\
\hline
\end{tabular}


physicians prior to it, having received one or more incorrect diagnoses, inappropriate treatments or having undergone unnecessary invasive procedures, as has also been described in other series [19-21].

This study does not come without limitations. The main one is the design of the study and the setting. It could be argued that a population-based study, resulting in a random sample of $\mathrm{CH}$ patients would be more appropriate and that $\mathrm{CH}$ patients who reach a specialist may represent an enriched population who would have atypical features or be more difficult to treat correctly. We believe our data do not point towards a highly enriched population. Patients visited us from all geographical regions of Greece, most patients came through self-referral (84.7\%), something quite common in Greece. Additionally, the majority of our cohort (57.9\%) were undiagnosed prior to visiting our clinic. Furthermore, extrapolating from the international $\mathrm{CH}$ prevalence data [9] to the Greek population (10.816.286 according to the last census) [39], an estimation of around $13.400 \mathrm{CH}$ patients are expected to live in Greece. In this case, our sample would represent a little more that $2 \%$ of the total $\mathrm{CH}$ patients in Greece.

\section{Conclusions}

Cluster headache, studied in a large cohort of Greek patients, has the well-documented general characteristics described in all Western populations. Despite the concept of a stereotyped clinical picture, atypical features are quite often present and physicians should be aware of those, as they usually may result in diagnostic problems. Most patients remain undiagnosed for a lengthy period of time; even when diagnosed, the treatment they receive remains far from optimal. On the other hand, our data show that time to diagnosis is improving, reaching a median period of one year for patients with recent onset. Educational activities for neurologists and other medical specialties that treat headache patients are critically important and should result in better recognition and treatment of cluster headache patients.

\section{Abbreviations}

$\mathrm{CCH}$ : Chronic cluster headache; $\mathrm{CH}$ : Cluster headache; ECH: Episodic cluster headache

\section{Acknowledgements}

The authors would like to thank Ms Evie Delicha for performing the statistical analysis and Dr. Georgios S. Vlachos for kindly reviewing the manuscript and providing fruitful comments.

\section{Funding}

No funding source had a role in the preparation and conduction of this study or in the preparation of the manuscript and the decision to submit it for publication.

\section{Authors' contributions}

MV designed the protocol, conducted the study and drafted the manuscript. Alan M. Rapoport critically reviewed the manuscript. Both authors approved the final manuscript.

\section{Competing interests}

MV has received honoraria and travel grants from Allergan, Greece, Brain Therapeutics, Greece and is an investigator in an Amgen-sponsored clinical trial on migraine prophylaxis. AMR has received honoraria for Ad Boards and consulting from several companies, but nothing related to this study.

\section{Disclosures}

Neither the authors or any immediate family member has financial relationships with commercial organizations that might appear to present a potential conflict of interest with the material presented.

\section{Author details}

${ }^{1}$ Headache Clinic, Mediterraneo Hospital, Glyfada, Greece. ${ }^{2}$ Glyfada Headache Clinic, 8 Lazaraki Str, Glyfada 16675, Greece. ${ }^{3}$ The David Geffen School of Medicine at UCLA, Los Angeles, California, USA.

Received: 13 August 2016 Accepted: 22 September 2016

Published online: 26 September 2016

\section{References}

1. Sjaastad O (ed) (1992) Cluster headache syndrome. WB Saunders, London

2. Sjaastad O, Nappi G (2000) Cluster headache syndrome in general practice: basic concepts. Smith-Gordon \& Co Ltd, London

3. Kudrow L (1980) Cluster headache: mechanisms and management. Oxford University Press, Oxford

4. Kudrow L (1997) Cluster headache. In: Goadsby PJ, Silberstein SD (eds) Headaches. Butterworth-Heinemann, Boston, pp 227-242

5. Gaul C, Diener HC, Müller OM (2011) Cluster headache-clinical features and therapeutic options. Dtsch Arztebl Int 108:543-549

6. May A, Bahra A, Büchel C, Frackowiak RS, Goadsby PJ (1998) Hypothalamic activation in cluster headache attacks. Lancet 25:275-278

7. Bahra A, May A, Goadsby PJ (2002) Cluster headache: a prospective clinical study with diagnostic implications. Neurology 58:354-361

8. Headache Classification Committee of the International Headache Society (IHS) (2013) The international classification of headache disorders, 3rd edition (beta version). Cephalalgia 33:629-808

9. Fischera M, Marziniak M, Gralow I, Evers S (2008) The incidence and prevalence of cluster headache: a meta-analysis of population-based studies. Cephalalgia 28:614-618

10. May A, Leone M, Afra J, Linde M, Sándor PS, Evers S, Goadsby PJ, EFNS Task Force (2006) EFNS guidelines on the treatment of cluster headache and other trigeminal-autonomic cephalalgias. Eur J Neurol 13:1066-1077

11. Ascherio A, Munger KL (2016) Epidemiology of multiple sclerosis: from risk factors to prevention-an update. Semin Neurol 36:103-114

12. Martelletti $P$, Mitsikostas DD (2015) Cluster headache: a quasi-rare disorder needing a reappraisal. J Headache Pain 16:59. doi:10.1 186/s10194-015-0545-1

13. Martelletti P (2015) Pharmacotherapy of cluster headache and beyond. Expert Opin Pharmacother 1:1-5

14. Rozen TD, Fishman RS (2012) Cluster headache in the United States of America: demographics, clinical characteristics, triggers, suicidality, and personal burden. Headache 52:99-113

15. Manzoni GC, Micieli G, Granella F, Tassorelli C, Zanferrari C, Cavallini A (1991) Cluster headache-course over ten years in 189 patients. Cephalalgia 11:169-174

16. Schürks M, Kurth T, de Jesus J, Jonjic M, Rosskopf D, Diener HC (2006) Cluster headache: clinical presentation, lifestyle features, and medical treatment. Headache 46:1246-1254

17. Donnet A, Lanteri-Minet M, Guegan-Massardier E, Mick G, Fabre N, Géraud G, Lucas C, Navez M, Valade D, on behalf of the Société Française d'Etude des Migraines et Céphalées (SFEMC) (2007) Chronic cluster headache: a French clinical descriptive study. Neurol Neurosurg Psychiatry 78:1354-1358

18. Lademann V, Jansen JP, Evers S, Frese A (2015) Evaluation of guideline-adherent treatment in cluster headache. Cephalalgia 36:760-764

19. Voiticovschi-losob C, Allena M, De Cillis I, Nappi G, Sjaastad O, Antonaci F (2014) Diagnostic and therapeutic errors in cluster headache: a hospitalbased study. J Headache Pain 15:56. doi:10.1186/1129-2377-15-566

20. Sánchez Del Rio M, Leira R, Pozo-Rosich P, Laínez JM, Alvarez R, Pascual J (2014) Errors in recognition and management are still frequent in patients with cluster headache. Eur Neurol 72:209-212

21. Bahra A, Goadsby PJ (2004) Diagnostic delays and mis-management in cluster headache. Acta Neurol Scand 109:175-179 
22. Robbins MS, Starling AJ, Pringsheim TM, Becker WJ, Schwedt TJ (2016) Treatment of cluster headache: the American Headache Society Evidence-Based Guidelines. Headache 56:1093-1106

23. Sarchielli P, Granella F, Prudenzano MP, Pini LA, Guidetti V, Bono G, Pinessi L, Alessandri M, Antonaci F, Fanciullacci M, Ferrari A, Guazzelli M, Nappi G, Sances G, Sandrini G, Savi L, Tassorelli C, Zanchin G (2012) Italian guidelines for primary headaches: 2012 revised version. J Headache Pain 13(Suppl 2):S31-S70

24. Petersen AS, Barloese MC, Jensen RH (2014) Oxygen treatment of cluster headache: a review. Cephalalgia 34:1079-1087

25. Costa A, Antonaci F, Ramusino MC, Nappi G (2015) The neuropharmacology of cluster headache and other trigeminal autonomic cephalalgias. Curr Neuropharmacol 13:304-323

26. Martelletti P, Curto M (2016) Cluster headache treatment - RCTs versus real-world evidence. Nat Rev Neurol. 12. doi: 10.1038/10.1038/nrneurol.2016

27. Antonaci F, Costa A, Ghirmai S, Sances G, Sjaastad O, Nappi G (2003) Parenteral indomethacin (the INDOTEST) in cluster headache. Cephalalgia 23:193-196

28. Antonaci F, Costa A, Candeloro E, Sjaastad O, Nappi G (2005) Single high-dose steroid treatment in episodic cluster headache. Cephalalgia 25:290-295

29. Matharu MS, Levy MJ, Meeran K, Goadsby PJ (2004) Subcutaneous octreotide in cluster headache: randomized placebo-controlled double-blind crossover study. Ann Neurol 56:488-494

30. Viana M, Tassorelli C, Allena M, Nappi G, Sjaastad O, Antonaci F (2013) Diagnostic and therapeutic errors in trigeminal autonomic cephalalgias and hemicrania continua: a systematic review. J Headache Pain 18:14

31. Manzoni GC, Taga A, Russo M, Torelli P (2016) Age of onset of episodic and chronic cluster headache - a review of a large case series from a single headache centre. J Headache Pain. 17:44. doi: 10.1186/s10194-016-0626-9

32. Manzoni GC (1998) Gender ratio of cluster headache over the years: a possible role of changes in lifestyle. Cephalalgia 18:138-142

33. Meyer EL, Laurell K, Artto V, Bendtsen L, Linde M, Kallela M, Tronvik E, Zwart $J A$, Jensen RM, Hagen K (2009) Lateralization in cluster headache: a Nordic multicenter study. J Headache Pain 10:259-263

34. Peatfield R (2001) Migrainous features in cluster headache. Curr Pain Headache Rep 5:67-70

35. Applebee AM, Shapiro RE (2007) Cluster-migraine: does it exist? Curr Pain Headache Rep 11:154-157

36. de Coo IF, Wilbrink LA, Haan J, Ferrari MD, Terwindt GM (2016) Evaluation of the new ICHD-III beta cluster headache criteria. Cephalalgia 36:547-551

37. Van Alboom E, Louis P, Van Zandijcke M, Crevits L, Vakaet A, Paemeleire K (2009) Diagnostic and therapeutic trajectory of cluster headache patients in Flanders. Acta Neurol Belg 109:10-17

38. Capobianco DJ, Dodick DW (2006) Diagnosis and treatment of cluster headache. Semin Neurol 26:242-259

39. Hellenic Statistical Authority. http://www.statistics.gr/2011-census-pop-hous. Accessed on 27 July 2016.

\section{Submit your manuscript to a SpringerOpen ${ }^{\circ}$ journal and benefit from:}

- Convenient online submission

- Rigorous peer review

- Immediate publication on acceptance

- Open access: articles freely available online

- High visibility within the field

- Retaining the copyright to your article 